\title{
Evaluation of tilapia skin gelatin as a mammalian gelatin replacer in acid milk gels and low-fat stirred yogurt
}

\author{
Zhihua Pang, ${ }^{*} \dagger$ Hilton Deeth, $†$ Hongshun Yang, $₫ \S$ Sangeeta Prakash, $†$ and Nidhi Bansal ${ }^{1}$ \\ *Beijing Advanced Innovation Center for Food Nutrition and Human Health, Beijing Technology and Business University, Beijing 100048, China \\ †School of Agriculture and Food Sciences, The University of Queensland, Brisbane, 4072, Australia \\ fFood Science and Technology Programme, Department of Chemistry, National University of Singapore, 117543, Singapore \\ §National University of Singapore (Suzhou) Research Institute, Suzhou, Jiangsu 215123, China
}

\begin{abstract}
Tilapia skin gelatin (TSG) was studied in a 3 -stage process (cooling, annealing, and heating) for pure gelatin gels and in a 4-stage process (acidification, cooling, annealing, and heating) for acid milk gels and cultured yogurt. The aim was to evaluate the use of TSG as a replacement for mammalian gelatin in yogurt. In pure TSG gels, stronger gels with higher melting temperatures were formed with increasing TSG concentrations. Compared with bovine gelatin (BG), which gelled at a concentration of $2.5 \%$, TSG gels had lower gelling $\left(14.1^{\circ} \mathrm{C}\right)$ and melting $\left(24^{\circ} \mathrm{C}\right)$ temperatures but comparable storage moduli during annealing. In acid milk gels, addition of TSG increased the firmness of the gels with increasing concentration. Gelling and melting points of TSG in milk gels were observed at sufficient concentrations during cooling and heating. Strands and sheets were observed in the electron micrographs of milk gels with 1\% TSG and a very dense structure was observed with $2.5 \%$ TSG. Yogurt with $0.4 \%$ TSG had similar viscosity, consistency, pseudoplasticity, and thixotropy as yogurt containing $0.4 \%$ BG; no difference was perceived by sensory panelists according to a triangle test. Addition of $0.4 \%$ TSG completely prevented whey separation from the acid milk gel and yogurt. The results suggest that TSG could be a suitable replacement for mammalian gelatin in low-fat stirred yogurt.
\end{abstract}

Key words: tilapia skin gelatin, yogurt, rheology, microstructure, sensory

\section{INTRODUCTION}

Gelatin is a multi-functional and most favored stabilizer in yogurt. It increases the gel strength, viscosity and water binding capacity of the yogurt, modifies the

Received August 16, 2016.

Accepted January 16, 2017.

${ }^{1}$ Corresponding author: n.bansal@uq.edu.au texture of the yogurt, stabilizes the yogurt system and, most uniquely, its melt-in-mouth property provides fat-like sensory perception to low-fat yogurt (Kalab et al., 1975; Fiszman and Salvador, 1999; Karim and Bhat, 2009). However, gelatin is mainly produced from pigskin, cattle bones, and cattle hide. Consumer groups with certain religious beliefs, such as Jews and Muslims, do not accept products made with such mammalian gelatin (Karim and Bhat, 2009).

There are also concerns about bovine spongiform encephalopathy (BSE), foot-and-mouth disease (FMD), and avian influenza with gelatin derived from mammals. Therefore, fish gelatin has been considered as a possible alternative to mammalian gelatin, especially since the outbreak of BSE in the 1980s. It meets the demands of the majority of consumers and complements the increasing global demand for gelatin (Karim and Bhat, 2009). The use of fish gelatin as an alternative to mammalian gelatin could reduce the volume of waste materials in the fish industry. Research has been carried out on methods of production of fish gelatin and its properties (Haug et al., 2004). In general, fish gelatin has some suboptimal physical properties compared with mammalian gelatin, particularly its low gelling and melting temperatures. The differences between fish and mammalian gelatins are due to the lower content of the imino acids proline (Pro) and hydroxyproline (Hyp) in fish gelatin. However, it was also found that the gel strength, gelling and melting temperature, and rheological properties are greatly influenced by the source of the fish gelatin (Zhou et al., 2006). In general, due to their higher imino acid content, the properties of gelatin from warm-water fish (e.g., tilapia, catfish, shark, and Nile perch), are closer to those of mammalian gelatin than those from cold-water fish (e.g., cod, salmon, and Alaska pollock; Zhou et al., 2006; Mahmoodani et al., 2014).

Tilapia is a warm-water fish species that is an important fishery resource. It is commonly farm raised, supplying a large quantity of fish skins as by-products, which have become the raw materials for gelatin pro- 
duction. Gelatin from tilapia contains around 79 Hyp and 119 Pro residues per 1,000 total residues (Sarabia et al., 2000), compared with 91 Hyp and 132 Pro in pork gelatin (Eastoe and Leach, 1977), and 96 Hyp and 123 Pro in bovine gelatin (Jellouli et al., 2011); it has physical properties similar to those of mammalian gelatin (Sarabia et al., 2000).

Fish gelatin has been suggested for use in yogurt (Karim and Bhat, 2009) but to date little has been reported on the effect of fish gelatin on yogurt properties. Therefore, in this work, we studied a fish gelatin from tilapia skin (TSG) with relatively high bloom and evaluated its potentiality for application in yogurt. The aim of this study was to evaluate TSG in yogurt as a possible replacement for mammalian gelatin. The study included an investigation of the behavior of pure TSG and the effects of TSG on acid milk gels.

\section{MATERIALS AND METHODS}

\section{Evaluation of Pure TSG Gel}

Commercial tilapia fish gelatin (200 Bloom) was purchased from Jiangxi Cosen Biology Co. Ltd. (Yingtan, China). The gelatin is a type A gelatin produced from tilapia fish skin. The mammalian gelatin, which was used in previous research and used for comparison in this study, was supplied by Gelita (Beaudesert, Australia); it was a light-colored edible bovine skin (type B) gelatin powder (200 Bloom). Solutions with 3 concentrations $(0.4,1$, and $2.5 \%, \mathrm{wt} / \mathrm{wt})$ of TSG were prepared by allowing the gelatin to swell in distilled water overnight (about $15 \mathrm{~h}$ ) followed by heating at $45^{\circ} \mathrm{C}$ for $30 \mathrm{~min}$ to dissolve it.

Dynamic oscillatory measurements were performed on a stress-controlled rheometer (model AR-G2, TA Instruments, Elstree, UK). Test samples were poured at $45^{\circ} \mathrm{C}$ onto the bottom plate of the rheometer, and a cone $\left(4 \mathrm{~cm}\right.$, diameter; $2^{\circ}$ angle) and plate geometry was used. A strain sweep revealed that $0.5 \%$ strain at a frequency of $1 \mathrm{~Hz}$ was within the linear viscoelastic region for the samples. The measurements were carried out in a 3-stage process - cooling, annealing, and heating - as described by Pang et al. (2015) with some modification: cooling $=$ equilibration at $30^{\circ} \mathrm{C}$ and a temperature sweep to $10^{\circ} \mathrm{C}$ at a cooling rate of $1^{\circ} \mathrm{C} /$ min to promote gelatin gel formation; annealing $=\mathrm{a}$ time sweep at $10^{\circ} \mathrm{C}$ for $1 \mathrm{~h}$ to observe the maturation of the gelling samples; heating $=$ a temperature sweep from 10 to $30^{\circ} \mathrm{C}$ at a heating rate of $1^{\circ} \mathrm{C} / \mathrm{min}$ to observe melting of the gelatin gels, which relates to the unique "melt-in-mouth" property of gelatin in yogurt.

The gelling and melting temperatures were calculated when there were appreciable increases and decreases, respectively, in complex viscosity $\left(\eta^{*}\right)$. The complex viscosity, $\eta^{*}$, was defined as in Eq. [1]:

$$
\eta^{*}=\sqrt{\mathrm{G}^{\prime 2}+\mathrm{G}^{\prime 2}} / \omega
$$

where $\mathrm{G}^{\prime}=$ storage modulus, $\mathrm{G}^{\prime \prime}=$ loss modulus, and $\omega=$ frequency. The crossover temperature was defined as when $G^{\prime \prime}$ equals $G^{\prime}$ (or the loss tangent, which is the ratio of $G^{\prime \prime}$ to $G^{\prime}$, was equal to 1 ); and the point of inflection was defined as the temperature of maximum or minimum change in complex viscosity per unit change in temperature. It was obtained by differentiating the complex viscosity with respect to temperature, $\mathrm{T}$ (first derivative, $\mathrm{d} \eta^{*} / \mathrm{dT}$ ) and finding the temperature at which the derivative was zero. All rheological measurements were performed in duplicate and the samples were randomized for the analysis (Pang et al., 2014).

\section{Evaluation of TSG in Stirred Acid Milk Gel}

Preparation of the Stirred Acid Milk Gels. Skim milk powder (SMP; protein 33\%, moisture 3.6\%, fat $0.9 \%$, lactose $54.7 \%$, and ash $7.8 \%$ ) was obtained from Murray Goulburn Co-Operative Ltd. (Melbourne, Australia). Reconstituted milk was prepared by dispersing the required amount of SMP in distilled water under continuous stirring for $30 \mathrm{~min}$ to obtain a milk protein concentration of $4.5 \%(\mathrm{wt} / \mathrm{wt})$. Three concentrations of TSG $(0.4,1.0$, and $2.5 \% \mathrm{wt} / \mathrm{wt})$ were added to the milk. All solutions were stored at $4^{\circ} \mathrm{C}$ overnight before use. The solutions were heated in a $95^{\circ} \mathrm{C}$ water bath for $10 \mathrm{~min}$ at their natural unadjusted $\mathrm{pH}$ and then cooled to $45^{\circ} \mathrm{C}$ immediately using cold water. Glucono$\delta$-lactone was added to the solutions at $1.5 \%$ (wt/wt) to decrease the $\mathrm{pH}$ to 4.6 in $4 \mathrm{~h}$ at $45^{\circ} \mathrm{C}$. A sample $(\sim 600 \mu \mathrm{L})$ was drawn to perform dynamic oscillatory measurements in a 4-stage process (acidification, cooling, annealing, and heating stage) as described below. The remaining sample was immediately transferred to a water bath at $45^{\circ} \mathrm{C}$ for acidification. After $4 \mathrm{~h}$ (at pH 4.6), the samples were stirred at 1,200 rpm for $2 \mathrm{~min}$ and stored at $10^{\circ} \mathrm{C}$ in an incubator.

Rheology. Samples were loaded onto a stresscontrolled rheometer (model AR-G2, TA Instruments) and measurement parameters similar to those used for pure TSG gels were applied. The samples were held at $45^{\circ} \mathrm{C}$ for $4 \mathrm{~h}$ (acidification); the temperature was then decreased to $10^{\circ} \mathrm{C}$ at a constant rate of $1^{\circ} \mathrm{C} / \mathrm{min}$ (cooling), maintained at $10^{\circ} \mathrm{C}$ for $2.5 \mathrm{~h}$ (annealing), and then increased to $45^{\circ} \mathrm{C}$ at $1{ }^{\circ} \mathrm{C} / \mathrm{min}$ (heating). Preliminary experiments for strain sweep showed that a strain of $0.5 \%$ was within the linear viscoelastic region for all samples at a frequency of $1 \mathrm{~Hz}$. The gelation point was 
defined as the point when a sharp increase in $\mathrm{G}^{\prime}$ from the baseline occurred. Two independent repetitions were conducted for each sample.

Microstructure. The microstructure of the samples was observed after $48 \mathrm{~h}$ storage at $10^{\circ} \mathrm{C}$, according to the methods described by Pang et al. (2015). Briefly, the samples were fixed with glutaraldehyde at room temperature and then dried with a $\mathrm{CO}_{2}$ critical point dryer (Tousimis Automatic, Rockville, MD). Dried samples were coated with platinum and observed with a scanning electron microscope (Jeol 6610, Jeol Ltd., Tokyo, Japan) at an acceleration voltage of $10 \mathrm{kV}$.

Texture Analysis. Texture profile analysis (TPA) was conducted on the samples after $48 \mathrm{~h}$ of storage at $10^{\circ} \mathrm{C}$ using a TA-XT2 Texture Analyzer (Godalming, UK), according to the methods described by Pang et al. (2015). The cylindrical probe with a flat base of $35 \mathrm{~mm}$ diameter was used. Two compression cycles were applied at a constant speed of $1 \mathrm{~mm} / \mathrm{s}$ to a sample depth of $10 \mathrm{~mm}$. The following parameters were quantified: firmness $(\mathrm{N})$, adhesiveness $(\mathrm{Nm})$, cohesiveness (ratio), and springiness $(\mathrm{mm})$. Three independent repetitions were conducted for each sample.

Water-Holding Capacity. Water-holding capacity (WHC) was determined by the method reported previously with a modified centrifuge speed (Pang et al., 2015). Samples were centrifuged at $200 \times g$ for $10 \mathrm{~min}$ at $10^{\circ} \mathrm{C}$ and $\mathrm{WHC}$ was defined as follows:

$$
\begin{gathered}
\text { WHC }(\%)=100(\text { MG weight }- \text { SE weight }) / \\
\text { MG weight, }
\end{gathered}
$$

where MG $=$ milk gel and SE $=$ serum expelled. Three independent repetitions were conducted for each sample.

\section{Evaluation of TSG in Yogurt}

Yogurt Preparation. Yogurt was prepared according to the method described in Pang et al. (2016). Briefly, TSG was added to the reconstituted milk (total solids $13.5 \%$, protein $4.5 \%$, fat $0.1 \%$, ash $1.1 \%$ ) at concentrations of 0.4 and $1 \%$ (wt/wt). The same concentrations were studied for bovine gelatin (Pang et al., 2016). One kilogram of the mixtures of SMP and TSG were heated to $95^{\circ} \mathrm{C}$ for $10 \mathrm{~min}$ in covered steel containers and cooled to $\sim 42^{\circ} \mathrm{C}$ immediately. At this point, the mixtures were inoculated with $0.2 \mathrm{U}$ of starter (YC-380; Streptococcus thermophilus and Lactobacillus delbrueckii ssp. bulgaricus, Chr. Hansen, Melbourne, Australia) per $\mathrm{kg}$ of culture and incubated at $42^{\circ} \mathrm{C}$ until $\mathrm{pH} 4.6$ was reached. Yogurts were then stirred at 1,200 rpm for 2 min and cooled immediately using iced water. Yogurt samples were evaluated after $48 \mathrm{~h}$ of storage at $4^{\circ} \mathrm{C}$. Yogurt production was performed in 2 independent replicates for all analyses. Microstructure, texture, and WHC of the yogurts were measured by the same methods as described above.

Rheology. Rheological properties (flow behavior and viscoelastic properties) were evaluated according to Pang et al. (2016). Briefly, shear stress was recorded at increasing shear rates (upward flow curve; from 0 to $100 \mathrm{~s}^{-1}$ ) and followed by decreasing shear rates (downward flow curve). The resulting upward flow curve was fitted to the Hershel-Bulkley model, which has been proven to give better fits to the upward flow curves than other models (power law or Casson; Hassan et al., 2003): $\sigma=\sigma_{0}+\mathrm{K} \dot{\gamma}^{n}$, where $\sigma=$ shear stress, $\sigma_{0}=$ yield stress, $\mathrm{K}=$ consistency index, $\dot{\gamma}=$ shear rate, and $n=$ flow behavior index. Other parameters such as the area under the upward flow curve $\left(\mathrm{A}_{\text {up }}\right)$ and the difference in area under the 2 curves $(\Delta \mathrm{A})$, as well as apparent vis$\operatorname{cosity}\left(\eta_{\text {app }}\right)$ were obtained. Frequency sweep was also carried out by increasing the frequency from 0.01 to 10 $\mathrm{Hz}$, and the applied strain was $0.5 \%$, which was within the linear viscoelastic range of the samples. The storage and loss moduli were recorded as a function of frequency.

Sensory. A sensory triangle test was also performed according to ISO 41:2004 (BS EN ISO 4120: 2004; ISO, 2004) with yogurt samples containing fish (FY) or bovine (BY) gelatin. Ten panelists, familiar with yogurt-type products, were recruited for the analysis. To increase the panelists' discriminative ability, six 1-h training sessions were performed before the triangle tests to help the panelists become familiar with the products and the mechanics of the triangle test. Analyses were conducted in individual tasting booths under red lights. Three randomly coded samples - 2 identical samples and 1 different sample-were presented to the panelists at $10^{\circ} \mathrm{C}$ in a randomized order. Panelists were asked to taste the samples in the order given, identify the different sample, and to note whether they were guessing. Panelists were provided with spring water to cleanse the palate between samples. In the cases where the different sample could not be identified, the panelists were forced to make a choice. Two replicates were conducted to improve the power of analysis.

\section{Statistical Analysis}

Minitab software (version 16; Minitab Inc., State College, PA) was used for ANOVA test of significance $(P<0.05)$. The results of the triangle test were analyzed using Chi-squared distribution. 


\section{RESULTS AND DISCUSSION}

\section{Evaluation of Pure TSG Gels}

Two trials were conducted for all the samples and similar trends were observed between the 2 replicates. The representative rheological results for TSG at 1 and $2.5 \%$ concentration, through the 3 stages (cooling, annealing, and heating) are shown in Figure 1 and the average values of $\mathrm{G}^{\prime}$ at the end of each stage were shown in Table 1. No gelation was observed at $0.4 \%$ concentration (data not shown). During cooling, only the $2.5 \%$ TSG gelled and the gelling temperature was calculated according to the method described by Pang et al. (2014). The TSG had a lower gelling temperature $\left(14.1^{\circ} \mathrm{C}\right)$ than the $\mathrm{BG}\left(17^{\circ} \mathrm{C}\right)$ at $2.5 \%$ concentration (Michon et al., 1993; Pang et al., 2014), which is attributable to the lower content of the imino acids (Pro and Hyp) in tilapia gelatin (198 per 1,000 amino acids) than BG (219 per 1,000 amino acids; Choi and Regenstein, 2000; Sarabia et al., 2000; Jellouli et al., 2011). A gelatin gel is a 3-dimensional helical network and the gelling temperature is the point at which the network first appears. The gelling requires a threshold level of polyproline II helices that form during cooling. Hydroxyl groups of the hydroxyproline play a role in the stability of the helices by hydrogen bonding (Jellouli et al., 2011; Pang et al., 2014). Therefore, gelatin, with a high content of imino acids, gels at a relatively high temperature. However, similar to BG, no gelation was observed for TSG at a concentration $\leq 1 \%$ during cooling (Pang et al., 2014).

During annealing, the rheograms were fitted to a modified first-order kinetic model (Eq. [2]; Pang et al., 2014). Within the time range studied (250 min), regression analysis revealed that the first-order kinetic model gave significant correlation coefficients $(P<0.05)$ greater than zero, suggesting that this model is suitable for describing the experimental data of this study:

$$
\begin{gathered}
\mathrm{G}^{\prime} t=\mathrm{G}_{0}{ }^{\prime}+\mathrm{G}_{\infty-0}{ }^{\prime}[1-\exp (-K t)], \\
\mathrm{G}_{\infty}{ }^{\prime}=\mathrm{G}_{0}{ }^{\prime}+\mathrm{G}_{\infty-0}{ }^{\prime},
\end{gathered}
$$

where $\mathrm{G}_{0}{ }^{\prime}=\mathrm{G}^{\prime}$ at time $t=0, \mathrm{G}_{\infty}{ }^{\prime}=\mathrm{G}^{\prime}$ at infinite time $(t \rightarrow \infty)$, and $K=$ rate of gelation during annealing. The $\mathrm{G}^{\prime}$ of $2.5 \%$ TSG increased from $\mathrm{G}_{0}{ }^{\prime}$ of $82.9 \mathrm{~Pa}$ to $\mathrm{G}_{\infty}{ }^{\prime}$ of $448.2 \mathrm{~Pa}$, with a gelation rate, $K$, of $3.7 \mathrm{E}^{-2}$; in comparison, gelation parameters for $\mathrm{BG}$ at $2.5 \%$ were as follows: $\mathrm{G}_{0}{ }^{\prime}=132.5 \mathrm{~Pa}, \mathrm{G}_{\infty}{ }^{\prime}=458$ $\mathrm{Pa}$, and $K=2.2 \mathrm{E}^{-2}$ (Pang et al., 2014). Therefore, the long-term storage modulus values were comparable but the gelation rate was higher for TSG than for BG. Arnesen and Gildberg (2007) reported that fish gela-
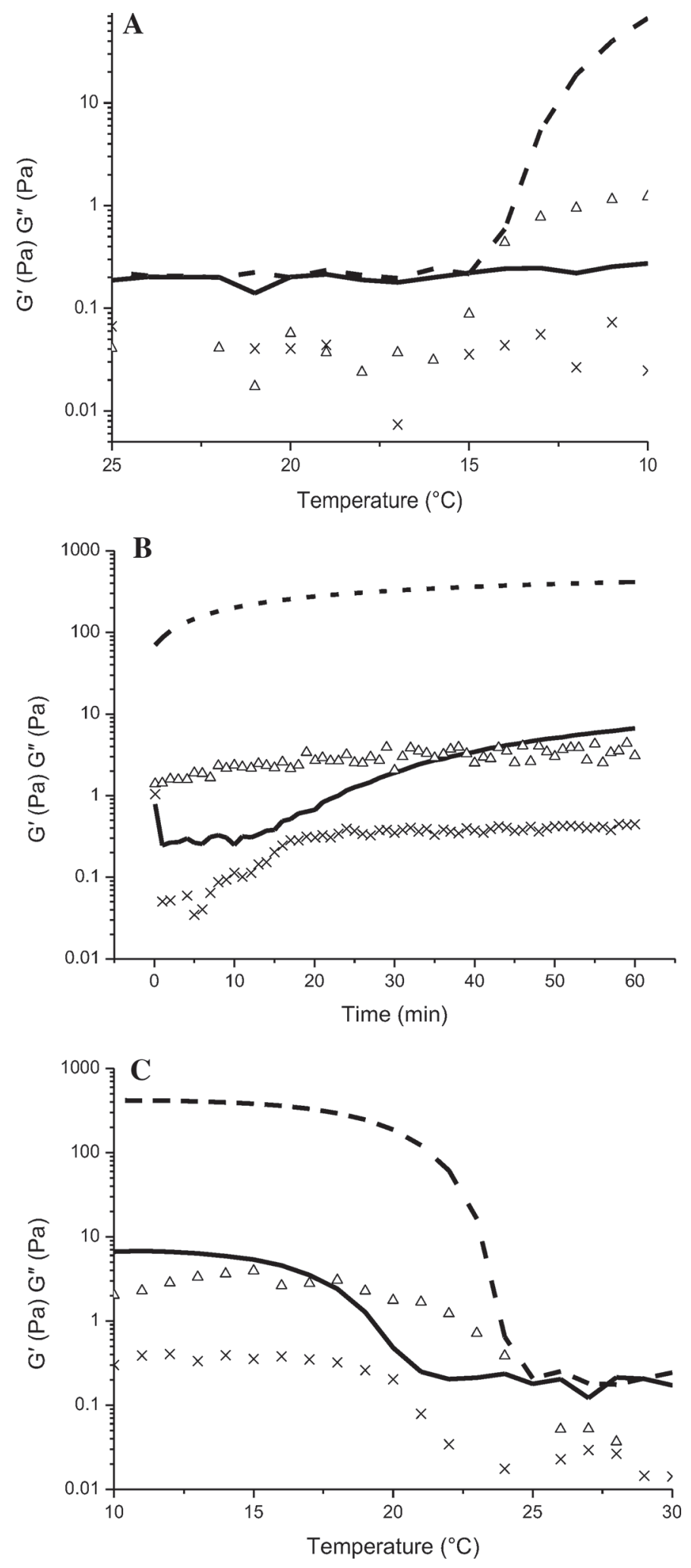

Figure 1. Changes in storage modulus $\left(\mathrm{G}^{\prime},-\right)$ and loss modulus $\left(\mathrm{G}^{\prime \prime}, \times\right)$ in $1 \%$ pure tilapia skin gelatin (TSG) gel and $\mathrm{G}^{\prime}(---)$ and $\mathrm{G}^{\prime \prime}(\Delta)$ in $2.5 \%$ pure TSG gel. (A) Cooling from 45 to $10^{\circ} \mathrm{C}$; (B) annealing at $10^{\circ} \mathrm{C}$; and $(\mathrm{C})$ heating from 10 to $30^{\circ} \mathrm{C}$. 
Table 1. Viscoelastic parameters of pure tilapia skin gelatin (TSG) gels and acid milk gels at the end of each stage during the dynamic oscillatory measurements ${ }^{1}$

\begin{tabular}{|c|c|c|c|c|c|c|}
\hline \multirow[b]{2}{*}{ Gel } & \multirow[b]{2}{*}{$\%$ TSG } & \multirow[b]{2}{*}{ Modulus } & \multicolumn{4}{|c|}{ Storage/loss modulus at the end of each stage $(\mathrm{Pa})$} \\
\hline & & & Acidification & Cooling & Annealing & Heating \\
\hline Pure TSG gel & 2.5 & $\mathrm{G}^{\prime}$ & & $68.85 \pm 2.79^{\mathrm{a}}$ & $420.7 \pm 8.2^{\mathrm{a}}$ & $0.258 \pm 0.02^{\mathrm{a}}$ \\
\hline \multirow{3}{*}{ Acid milk gels with TSG } & 0 & $\mathrm{G}^{\prime}$ & $587.65 \pm 19.3^{\mathrm{a}}$ & $2,436.5 \pm 193^{\mathrm{a}}$ & $2,412 \pm 171.1^{\mathrm{b}}$ & $581.35 \pm 35.3^{\mathrm{a}}$ \\
\hline & 0.4 & $\mathrm{G}^{\prime}$ & $504 \pm 35.07^{\mathrm{ab}}$ & $2,122 \pm 138.59^{\mathrm{a}}$ & $2,152 \pm 43.84^{\mathrm{b}}$ & $520.15 \pm 2.9^{\mathrm{a}}$ \\
\hline & 1.0 & $\mathrm{G}^{\prime}$ & $486 \pm 23.19^{\mathrm{b}}$ & $2,089 \pm 74.25^{\mathrm{a}}$ & $2,297.5 \pm 105.4^{\mathrm{b}}$ & $529.5 \pm 22.9^{\mathrm{a}}$ \\
\hline
\end{tabular}

${ }_{\mathrm{a}, \mathrm{b}}$ Mean values within a column and within a gel type with different letters are significantly different $(P<0.05)$.

${ }^{1}$ Values are presented as mean $\pm \mathrm{SD}$.

tins from salmon (108 g) and cod (71 g) had lower gel strengths than porcine gelatin $(216 \mathrm{~g})$ but much higher gel strengthening rates during annealing, which could result in relatively high gel strength during long-term storage. Arnesen and Gildberg (2007) suggested that the gel strengthening of gelatin was attributable not only to the regeneration of helical structures between collagen peptide chains, but also to the formation of hydrogen bonds between hydroxylated amino acids and incorporated water molecules. Weak gelation was also observed for 1\% TSG after about 22 min of this stage, although $\mathrm{G}^{\prime}$ remained below $10 \mathrm{~Pa}$; no gelation was observed for $0.4 \%$ TSG. This result was in agreement with the theory that gelation only occurs when the gelatin concentration is greater than its critical gelling concentration, typically 0.4 to $1 \%$, depending on the gelatin type (Djabourov et al., 1993).

During heating, $\mathrm{G}^{\prime}$ of the gels decreased rapidly and melting temperatures of the 1 and $2.5 \%$ TSG gels were 20.4 and $24^{\circ} \mathrm{C}$, respectively. A higher concentration of TSG leads to shorter distances between gelatin coils; thus, more and stronger junction zones are formed and a higher temperature is needed to melt the structure (Haug et al., 2004). The melting temperatures for $\mathrm{BG}$ were 25 to $27^{\circ} \mathrm{C}$ and 27 to $32^{\circ} \mathrm{C}$ for 1 and $2.5 \%$, respectively (Pang et al., 2014). The lower melting temperature of TSG gels may also be related to its lower content of proline and hydroxyproline (Choi and Regenstein, 2000). The melting of a gelatin gel is the reverse process of gelling during which the helical structure converts to coils, and the stability of the helices is related to the content of imino acids (Jellouli et al., 2011; Pang et al., 2014).

\section{Evaluation of TSG in Stirred Acid Milk Gel}

Rheology. Representative rheological results of samples with different concentrations of TSG during the 4 stages are shown in Figure 2, and the average values of $\mathrm{G}^{\prime}$ at the end of each stage are shown in
Table 1. Two trials were conducted for all samples and similar trends were observed between the 2 replicates. During acidification (Figure 2a), addition of TSG did not change the rheological profile of the milk gel, but a slight decrease in $\mathrm{G}^{\prime}$ was observed at all concentrations of TSG and a lower $\mathrm{G}^{\prime}$ value was observed at higher TSG concentration; this could be due to steric interference of the formation of the milk gel (Loren et al., 1999) as reported for BG in acid milk gels (Pang et al., 2015). At this stage, TSG could not form a gel because of the high temperature, and milk proteins were the dominating gelling agents during acidification. Gelatin seemed to interrupt the acid gelation of milk proteins in its coiled (ungelled) form. Moreover, TSG is a type A gelatin with an isoelectric point $(\mathrm{pI})$ around 9.0. The molecules were positively charged in the acid milk gel system, whereas casein carried some negative charge at $\mathrm{pH}$ above 4.6. Therefore, interactions between TSG and caseins may occur during acidification, which could affect the formation of the casein network and reduce the gel strength. During cooling (Figure 2b), the $\mathrm{G}^{\prime}$ of all gels increased rapidly. The decreasing temperature could have caused a decreased number or strength of hydrophobic bonds inside the casein particles, which results in an increase in voluminosity of the particles, and hence a swelling of the casein particles, and an increase in the number of inter-particle bonds, and $\mathrm{G}^{\prime}$. Moreover, the cooling process leads to a conformational change of gelatin from coil to helix, reinforced by hydrogen bonds, which was also reflected in an increase in G' (Lucey et al., 1997; Pang et al., 2014). The sample with 2.5\% TSG showed an inflection between 13 and $14^{\circ} \mathrm{C}$, which was the gelling temperature of the $2.5 \%$ TSG gel, as seen in Figure 1. The $\mathrm{G}^{\prime}$ of this sample increased much faster after the gelling point and reached the value of the sample without TSG at the end of this stage. The acid milk gels with 0.4 and $1 \%$ TSG did not show any inflection, which corresponded to the fact that fish gelatin did not gel during cooling at these concentrations. During annealing (Figure 2c), 
gels without and with $0.4 \%$ TSG did not show much change, corresponding to the fact that $0.4 \%$ TSG did not gel during the whole process; gels with 1\% TSG showed an increase of $\mathrm{G}^{\prime}$ due to gelation. A dramatic increase in $\mathrm{G}^{\prime}$ was observed for the sample with $2.5 \%$ TSG due to further gelation of gelatin. During heating (Figure 2d), the $\mathrm{G}^{\prime}$ of all samples decreased rapidly, especially the sample with $2.5 \%$ TSG. Shrinkage of the casein particles due to increased hydrophobic bonds at higher temperatures may be responsible for this decrease (Lucey et al., 1997). Inflections were observed for samples with 1 and $2.5 \%$ fish gelatin at 23 and $26^{\circ} \mathrm{C}$, respectively, indicating melting of the gelatin gel in the acid milk gels. A higher melting temperature of these gels than that of the pure TSG gel was observed. Similar results were reported previously, whereby SMP increased the melting temperature of BG gels, which was attributed to stabilization of the network by SMP through changes in hydrogen bonding, which is the basis of the formation of the gelatin network (Pang et al., 2014). The final $\mathrm{G}^{\prime}$ of all the samples reached similar values $(581,520,529$, and $492 \mathrm{~Pa}$ ) for samples without and with $0.4,1$, and $2.5 \%$ TSG, respectively) at the end of this stage, suggesting that gelation and melting of the fish gelatin had little influence on the continuity of the gels. Similar results were reported for BG (Cooney et al., 1993; Walkenstrom and Hermansson, 1994, 1996; Pang et al., 2015).

Microstructure. The micrographs of acid milk gels with different concentrations of TSG are shown in Figure 3. After $48 \mathrm{~h}$ of storage at $10^{\circ} \mathrm{C}$, no gelation occurred in the sample with $0.4 \%$ fish gelatin and the microstructure observed (Figure $3 \mathrm{~b}$ ) was similar to that of the pure acid SMP gel (Figure 3a), which corresponded to the $0.4 \%$ gelatin that also did not gel (Figure 1). With 1\% TSG, a thin gelatin structure was clearly seen throughout the gel network, with strands and sheets connecting the casein particle clusters; with $2.5 \%$ TSG, the gel structure was very dense with almost no voids. It should be noted that addition of either 1 or $2.5 \%$ TSG did not change the milk gel network and the typical casein gel structure was maintained. Similar microstructure results were reported for acid milk gels with BG, and milk gels with some polysaccharides (Sanchez et al., 2000; Cavallieri and Cunha, 2009; de Jong et al., 2009; Pang et al., 2015).

Texture Analysis and $\boldsymbol{W H C}$. Texture is one of the most important properties of yogurt because it directly influences sensory perception by consumers. Addition of stabilizers, including gelatin, is able to modify the texture (Bourne, 2002; Paseephol et al., 2008). Whey separation or syneresis is a major problem in yogurt and it occurs during storage when the gel network re- arranges and expels moisture (Keogh and O'Kennedy, 1998). Bovine gelatin, which becomes functional at low temperature, greatly increases the WHC of acid milk gels and markedly reduces whey separation (Pang et al., 2015).

Table 2 shows the texture and WHC results of stirred acid milk gels without TSG and with different concentrations of TSG. The firmness of the gels was not changed by addition of $0.4 \%$ TSG but significantly increased by addition of 1 and $2.5 \%(P<0.05)$; similar results were reported for BG (Pang et al., 2015). Firmness is related to the strength of the gel structure under compression (Bourne, 2002). The milk gel with $2.5 \%$ TSG showed extremely high firmness (12.8 N) compared with other samples. Tilapia skin gel, which reinforced the strength of the mixed gels, plays an important role in the increase in firmness. Cohesiveness indicates the degree of difficulty in breaking down the gel's internal structure (Bourne, 2002). The cohesiveness of the samples decreased significantly $(P<0.05)$ with increasing concentration of TSG up to $1 \%$, which could be related to steric interference by the addition of gelatin; however, it increased significantly $(P<0.05)$ in samples with $2.5 \%$. Adhesiveness is a surface characteristic and is determined by a combined effect of adhesive and cohesive forces, viscosity, and viscoelastic properties (Adhikari et al., 2001). Adhesiveness increased with increasing concentration of TSG up to $1 \%$ and then decreased with increasing TSG concentration up to $2.5 \%$. It has been reported that an open and loose protein matrix tends to show high adhesiveness (Rahman and AI-Mahrouqi, 2009). From the microstructure results (Figure 3), it can be seen that low concentrations of TSG (0.4 and 1\%) did not change the milk gel matrix much, whereas the high concentration of TSG $(2.5 \%)$ led to a more compact protein gel matrix; thus, low adhesiveness was obtained for this sample.

According to the WHC results, TSG could effectively prevent syneresis of the milk gels, which is similar to the effect of BG (Pang et al., 2015). No whey separation was observed with addition of TSG at a concentration as low as $0.4 \%$. The water-binding property of gelatin is related to its conformational change from coil to helix, which involves water molecules as "structural water" (Maquet et al., 1986), and its immobilization of the aqueous phase in the milk gel network.

\section{Evaluation of TSG in Cultured Yogurt}

From the results of the acid milk gels, addition of TSG at $2.5 \%$ led to a much firmer gel than a pure milk gel, which indicates this concentration is not suitable for yogurt application. Therefore, addition levels of 

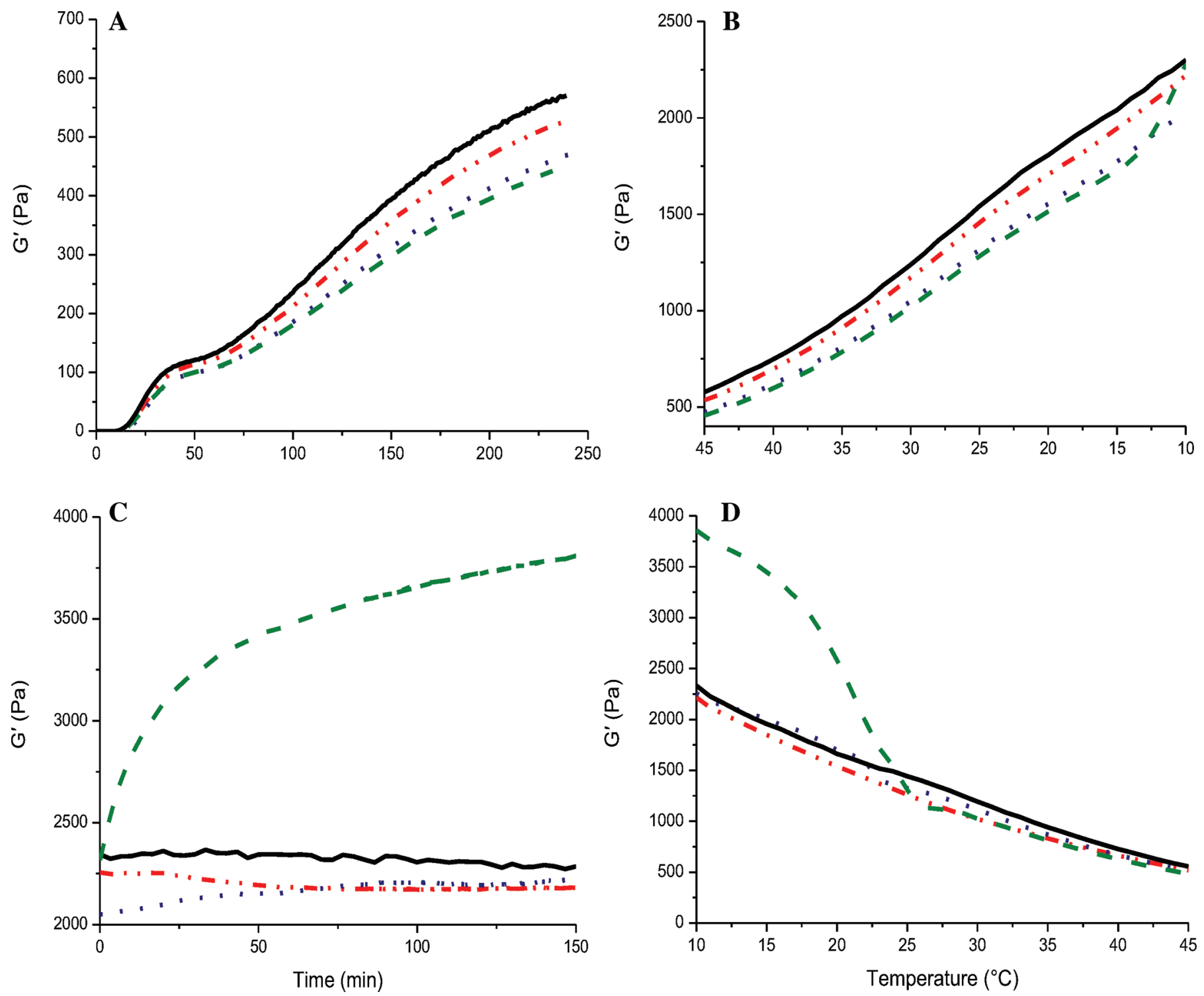

Figure 2. Changes in storage modulus $\left(\mathrm{G}^{\prime}\right)$ of acid milk gels without (-, black) or with $0.4 \%(-. \cdot-$, red $), 1.0 \%(\cdots$, blue $)$ and $2.5 \%(---$, green) tilapia skin gelatin (TSG). (A) Acidification at $45^{\circ} \mathrm{C}$; (B) cooling from 45 to $10^{\circ} \mathrm{C}$; (C) annealing at $10^{\circ} \mathrm{C}$; and (D) heating from 10 to $45^{\circ} \mathrm{C}$. Color version available online.

Table 2. Effect of tilapia skin gelatin (TSG) on texture parameters and water-holding capacity (WHC) of acid milk protein gels ${ }^{1}$

\begin{tabular}{lcccc}
\hline $\begin{array}{l}\text { TSG in acid } \\
\text { milk gel }(\%)\end{array}$ & Firmness (N) & Cohesiveness (ratio) & Adhesiveness (Nm) & WHC (\%) \\
\hline 0 & $0.404 \pm 0.012^{\mathrm{c}}$ & $0.624 \pm 0.009^{\mathrm{b}}$ & $0.152 \pm 0.029^{\mathrm{c}}$ & $94.98 \pm 0.263^{\mathrm{b}}$ \\
0.4 & $0.678 \pm 0.04^{\mathrm{c}}$ & $0.595 \pm 0.007^{\mathrm{c}}$ & $0.575 \pm 0.033^{\mathrm{b}}$ & $100 \pm 0^{\mathrm{a}}$ \\
1.0 & $3.197 \pm 0.1^{\mathrm{b}}$ & $0.561 \pm 0.008^{\mathrm{d}}$ & $0.748 \pm 0.128^{\mathrm{a}}$ & $100 \pm 0^{\mathrm{a}}$ \\
2.5 & $12.8 \pm 0.893^{\mathrm{a}}$ & $0.793 \pm 0.012^{\mathrm{a}}$ & $0.22 \pm 0.028^{\mathrm{c}}$ & $100 \pm 0^{\mathrm{a}}$ \\
\hline
\end{tabular}

${ }^{\mathrm{a}-\mathrm{d}}$ Means within a column with different letters are significantly different $(P<0.05)$.

${ }^{1}$ Values are presented as mean $\pm \mathrm{SD}$. 

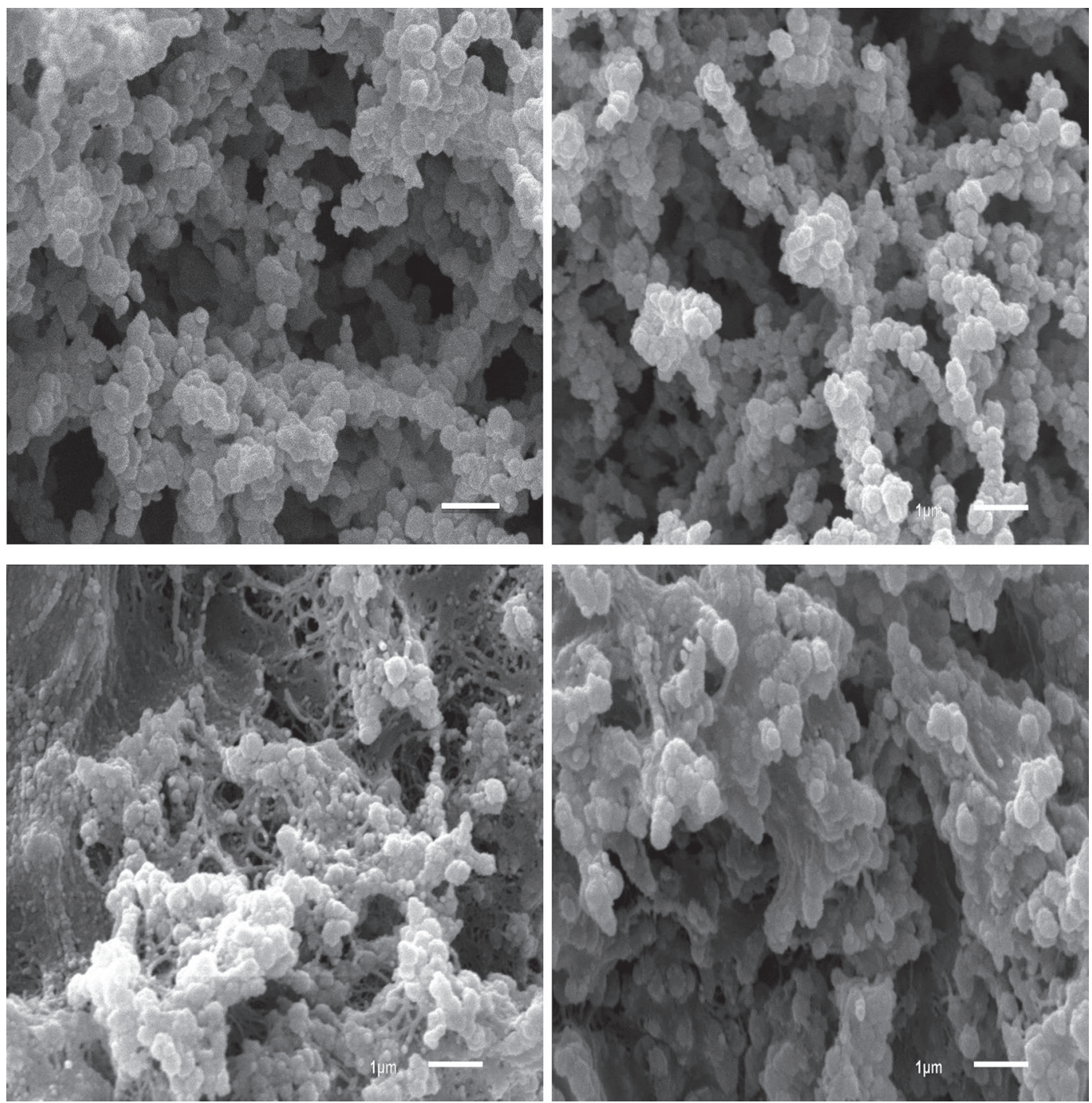

Figure 3. Scanning electron micrographs of acid milk gels without (A) or with 0.4 (B), 1 (C), and 2.5\% (D) (wt/wt) tilapia skin gelatin (TSG) after $48 \mathrm{~h}$ of storage at $10^{\circ} \mathrm{C}$. Scale bars $=1 \mu \mathrm{m}$.

0.4 and $1 \%$ TSG only were studied in cultured yogurt. Yogurt with $0.4 \%$ BG was included for comparative purposes.

Texture Analysis and WHC. It can be seen from Table 3 that, similar to the results for the acid milk gels, TSG increased the firmness and adhesiveness and decreased the cohesiveness of yogurt. Comparing TSG and BG at an addition level of $0.4 \%$, TSG induced higher gel firmness and lower cohesiveness than BG, which could be related to their different amino acid

Table 3. Effect of tilapia skin gelatin (TSG) and bovine gelatin (BG) on texture parameters and water-holding capacity (WHC) of cultured yogurt ${ }^{1}$

\begin{tabular}{lcccc}
\hline Sample & Firmness $(\mathrm{N})$ & Cohesiveness (ratio) & Adhesiveness (Nm) & WHC (\%) \\
\hline $0 \%$ gelatin & $0.24 \pm 0.01^{\mathrm{c}}$ & $0.78 \pm 0.03^{\mathrm{a}}$ & $0.09 \pm 0.06^{\mathrm{c}}$ & $97.2 \pm 0.19^{\mathrm{b}}$ \\
$0.4 \%$ BG & $0.32 \pm 0.03^{\mathrm{c}}$ & $0.69 \pm 0.04^{\mathrm{b}}$ & $0.18 \pm 0.06^{\mathrm{ab}}$ & $100 \pm 0^{\mathrm{a}}$ \\
$0.4 \%$ TSG & $0.49 \pm 0.04^{\mathrm{b}}$ & $0.61 \pm 0.01^{\mathrm{c}}$ & $0.15 \pm 0.03^{\mathrm{bc}}$ & $100 \pm 0^{\mathrm{a}}$ \\
$1.0 \%$ TSG & $3.58 \pm 0.04^{\mathrm{a}}$ & $0.60 \pm 0.04^{\mathrm{c}}$ & $0.25 \pm 0.07^{\mathrm{a}}$ & $100 \pm 0^{\mathrm{a}}$ \\
\hline
\end{tabular}

${ }^{\mathrm{a}-\mathrm{c}}$ Means within a column with different letters are significantly different $(P<0.05)$.

${ }^{1}$ Values are presented as mean $\pm \mathrm{SD}$. 


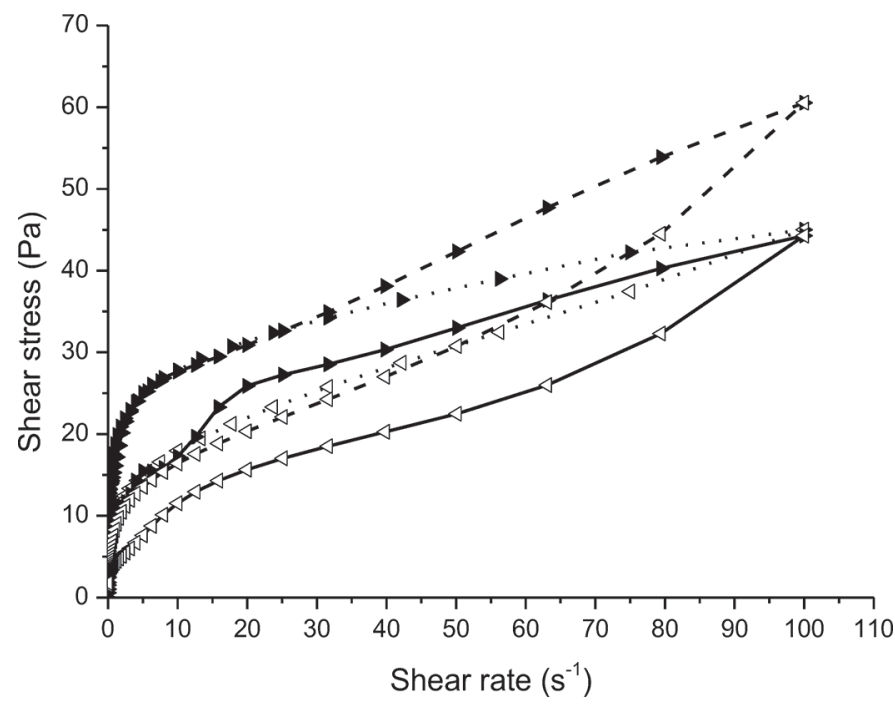

Figure 4. Flow curves of yogurts without gelatin $(\mathrm{CY},-)$, with bovine gelatin $(\mathrm{BY},---)$, and with fish gelatin $(\mathrm{FY}, \cdots)$. Shear rate was first increased $(\boldsymbol{\Lambda})$ and then decreased $(\Delta)$. Measurement temperature was $4^{\circ} \mathrm{C}$.

compositions. The yogurt containing $1 \%$ TSG was significantly firmer than the yogurts with $0.4 \%$ TSG or BG. No serum expulsion was observed in any yogurt containing TSG.

Rheology. From the texture results, the yogurt with 1\% TSG was much firmer than the control yogurt $(\sim 15$-fold $)$ and the sample did not have the viscous property of a stirred yogurt. Therefore, it was not evaluated in the subsequent rheology, microstructure, and sensory studies. Figure 4 shows flow curves of yogurts with shear rate plotted versus shear stress. All yogurts showed hysteresis loops and shear thinning (thixotropic) behavior. Paseephol et al. (2008) reported similar observations for set yogurt. The yogurts with fish gelatin (FY) or bovine gelatin (BY) had higher shear stress values than the control yogurt without gelatin $(\mathbf{C Y})$, indicating that a stronger gel structure was formed with higher resistance to shear forces (Ares et al., 2007). Furthermore, FY showed shear stress values very close to those of $\mathrm{BY}$ at shear rates lower than $\sim 30 \mathrm{~s}^{-1}$ but much lower values at higher shear rates.
Compared with CY, FY showed higher shear stress at low shear rates, but almost the same value as CY at higher shear rates. The results can be interpreted as greater structural damage in FY at the higher shear rates, whereas $\mathrm{CY}$ and $\mathrm{BY}$ were more stable to these shear forces (Saint-Eve et al., 2006).

The upward curves were fitted to the HerschelBulkley model and the resulting parameters are shown in Table 4. The model fitted the experimental data satisfactorily for all samples, showing $\mathrm{R}^{2}$ values generally above 0.96 (data not shown). Yield stress was not found in FY, whereas BY and CY showed positive yield stress with lower values being observed in $\mathrm{BY}$, indicating that a lower shear stress was required for flow to commence and that FY and BY were less resistant to shearing than CY. Hassan et al. (2003) reported that yogurts made with ropy strains showed no yield stress or much lower yield stress values than those made with non-ropy strains; this was attributed to the presence of exopolysaccharides in the continuous phase that decreased interactions between the protein aggregates during shearing. We can hypothesize that a similar interference in the protein network may have occurred with the addition of gelatins. Apart from the first yield point, CY showed a small shear stress peak at a shear rate of $\sim 4.5 \mathrm{~s}^{-1}$ in the upward flow curve, but neither BY nor FY showed this peak (Figure 4). This observation has not been reported before and further investigation is required to determine the significance of the peak. The consistency coefficient $(\mathrm{K})$ was higher in BY and FY than in CY. The results were generally in agreement with previous research showing that gelatin increased K (Keogh and O'Kennedy, 1998; Ares et al., 2007). Flow index $(n)$, which is a measure of deviation of shear thinning fluids from Newtonian flow, was lower in BY and FY than in CY, indicating that addition of either bovine or fish gelatin increased the pseudoplastic behavior of yogurt. Similar results were reported for gelatin in yogurt by Keogh and O'Kennedy (1998) and Ares et al. (2007). They also concluded that greater shear thinning occurred with an increase of $\mathrm{K}$.

The apparent viscosity $\left(\eta_{\text {app }}\right)$ of yogurts was measured at a shear rate of $50 \mathrm{~s}^{-1}$, which was reported

Table 4. Rheological parameters from flow curve of cultured yogurts ${ }^{1}$

\begin{tabular}{|c|c|c|c|c|c|c|}
\hline Sample $^{2}$ & $\begin{array}{l}\text { Yield stress } \\
\sigma_{0}(\mathrm{~Pa})\end{array}$ & $\begin{array}{c}\text { Consistency } \\
\text { coefficient K }\left(\mathrm{Pa} \cdot \mathrm{s}^{n}\right)\end{array}$ & $\begin{array}{l}\text { Flow behavior } \\
\text { index }(n)\end{array}$ & $\begin{array}{c}\text { Area under up-curve } \\
\qquad \mathrm{A}_{\mathrm{up}}\left(\mathrm{s}^{-1} \cdot \mathrm{Pa}\right)\end{array}$ & $\begin{array}{c}\text { Area } \\
\text { difference } \Delta \mathrm{A}\end{array}$ & $\begin{array}{l}\text { Apparent viscosity } \\
\left(50 \mathrm{~s}^{-1}\right)(\mathrm{Pa} \cdot \mathrm{s})\end{array}$ \\
\hline$\overline{\mathrm{CY}}$ & $9.9 \pm 1.43^{\mathrm{a}}$ & $1.42 \pm 0.97^{\mathrm{c}}$ & $0.73 \pm 0.17^{\mathrm{a}}$ & $2,815 \pm 557^{\mathrm{b}}$ & $761 \pm 227^{\mathrm{ab}}$ & $0.58 \pm 0.11^{\mathrm{b}}$ \\
\hline BY & $6.13 \pm 1.76^{\mathrm{b}}$ & $10.52 \pm 2.54^{\mathrm{b}}$ & $0.3 \pm 0.05^{\mathrm{b}}$ & $3,819 \pm 572^{\mathrm{a}}$ & $919 \pm 148^{\mathrm{a}}$ & $0.75 \pm 0.12^{\mathrm{a}}$ \\
\hline
\end{tabular}

${ }^{a-c}$ Means within a column with different letters are significantly different $(P<0.05)$.

${ }^{1}$ Values are presented as mean $\pm \mathrm{SD}$.

${ }^{2} \mathrm{CY}=$ control yogurt; $\mathrm{BY}=$ yogurt with $0.4 \%$ bovine gelatin; $\mathrm{FY}=$ yogurt with $0.4 \%$ fish gelatin . 


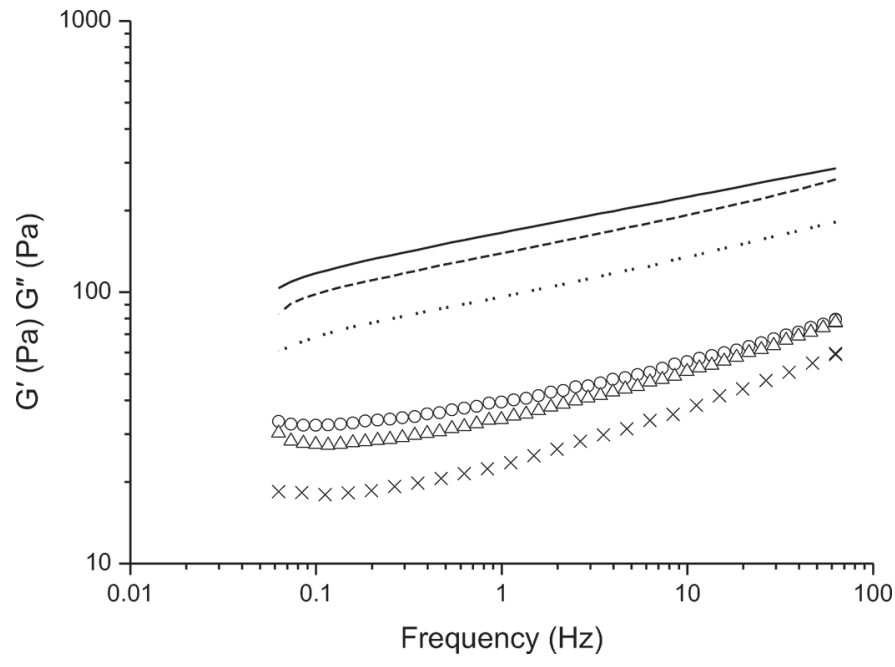

Figure 5. Frequency sweeps of cultured yogurts at $4^{\circ} \mathrm{C}$. Yogurt without gelatin $\left(\mathrm{CY} ; \mathrm{G}^{\prime}-, \mathrm{G}^{\prime \prime} \mathrm{O}\right)$, with bovine gelatin $\left(\mathrm{BY} ; \mathrm{G}^{\prime}---\right.$, $\left.G^{\prime \prime} \Delta\right)$, and with fish gelatin $\left(F Y ; G^{\prime} \cdots, G^{\prime \prime} \times\right) . G^{\prime}=$ storage modulus, $\mathrm{G}^{\prime \prime}=$ loss modulus.

as an effective oral shear rate (Marcotte et al., 2001). The BY samples had higher $\eta_{\text {app }}$ than CY samples, and no significant difference was observed between BY and FY. The increase in apparent viscosity of yogurt by addition of gelatin is reported to be due to the interaction between gelatin and milk proteins (Ares et al., 2007; Teles and Flores, 2007). Therefore, fish gelatin can provide high viscosity to yogurt but its low gelation temperature is generally regarded as an inferior property (Leuenberger, 1991). However, at a concentration of less than $1 \%$, which is a common application level of gelatin in yogurt (Kumar and Mishra, 2004; Ares et al., 2007), fish gelatin does not gel in yogurt. Therefore, the low gelation temperature may not be a problem for its application in yogurt.

The area of the hysteresis loop $(\Delta \mathrm{A})$, an indication of structural breakdown and rebuilding during shearing (thixotropy), was also calculated. The BY samples had a higher $\Delta \mathrm{A}$ value than $\mathrm{FY}$, indicating that $\mathrm{BY}$ was more susceptible to structural breakdown by the application of shear stress than FY and that restructuring of the protein aggregates into a coherent network structure after shearing was more difficult for BY than for FY (Amatayakul et al., 2006; Ares et al., 2007). This could be due to the inherent differences in the structure of 2 types of gelatin; fish gelatin generally has more native protein structure, whereas bovine gelatin has a more aggregated and hydrolyzed structure due to a much more aggressive extraction procedure (Karim and Bhat, 2009).

The frequency dependence of yogurts was shown by plotting $\log \mathrm{G}^{\prime}$ and $\log \mathrm{G}^{\prime \prime}$ versus $\log \omega$ (Figure 5). All yogurts exhibited viscoelastic characteristics, with $\mathrm{G}^{\prime}$ being higher than $\mathrm{G}^{\prime \prime}$ during the entire frequency range. The slope of the line was found to be higher for BY and FY than for CY (Table 5), indicating the modulus was more frequency-dependent and the gel was more viscous in BY and FY than in CY (Hassan et al., 1995). The moduli at frequency $(\omega)$ of $1 \mathrm{~Hz}$ are shown in Table 5. The FY samples had lower $\mathrm{G}^{\prime}$ and $\mathrm{G}^{\prime \prime}$ than CY samples, and there was no significant difference between $\mathrm{CY}$ and BY, indicating that weaker yogurt gels were formed with fish gelatin. The results were in accordance with reports that rheological gel strength is not correlated with firmness from texture analyses due to the differences in sample deformation between the 2 techniques (Beaulieu et al., 2001) and that viscoelasticity would be more related to the interaction between aggregates during oscillation (Hassan et al., 2003).

Microstructure and Sensory Analysis. The microstructure of yogurts is shown in Figure 6. The FY and BY samples had very similar microstructures at a gelatin concentration of $0.4 \%$. The milk protein networks in these 2 yogurts were similar and the typical casein network was maintained.

A sensory discrimination test was conducted to determine if a difference existed between $\mathrm{FY}$ and $\mathrm{BY}$. A Chi-squared distribution of the results of 10 panelists showed that no difference was perceived by the panelists. Both yogurts were described as smooth and viscous by the panelists.

Table 5. Viscoelastic parameters ${ }^{1}$ of cultured yogurts from frequency sweeps ${ }^{2}$

\begin{tabular}{lccccc}
\hline Sample $^{3}$ & $\mathrm{G}^{\prime}$, at $1 \mathrm{~Hz}$ & $\mathrm{G}^{\prime \prime}$, at $1 \mathrm{~Hz}$ & $\begin{array}{c}\text { Loss tangent } \delta, \\
\text { at } 1 \mathrm{~Hz}\end{array}$ & $\begin{array}{c}\text { Slope of log }\left(\mathrm{G}^{\prime}\right) \\
\text { vs. frequency }\end{array}$ & $\begin{array}{c}\text { Slope of log }\left(\mathrm{G}^{\prime \prime}\right) \\
\text { vs. frequency }\end{array}$ \\
\hline $\mathrm{CY}$ & $151.7 \pm 19.3^{\mathrm{a}}$ & $35.9 \pm 4.4^{\mathrm{a}}$ & $0.24 \pm 0.004^{\mathrm{a}}$ & $0.14 \pm 0.004^{\mathrm{b}}$ & $0.14 \pm 0.007^{\mathrm{c}}$ \\
$\mathrm{BY}$ & $137.8 \pm 164^{\mathrm{a}}$ & $33.8 \pm 4.2^{\mathrm{a}}$ & $0.25 \pm 0.004^{\mathrm{a}}$ & $0.15 \pm 0.003^{\mathrm{a}}$ & $0.16 \pm 0.003^{\mathrm{b}}$ \\
FY & $95.9 \pm 5.9^{\mathrm{b}}$ & $23.3 \pm 1.3^{\mathrm{b}}$ & $0.24 \pm 0.004^{\mathrm{a}}$ & $0.15 \pm 0.004^{\mathrm{a}}$ & $0.19 \pm 0.009^{\mathrm{a}}$ \\
\hline
\end{tabular}

${ }^{\mathrm{a}-\mathrm{c}}$ Means within a column with different letters are significantly different $(P<0.05)$.

${ }^{1} \mathrm{G}^{\prime}=$ storage modulus, $\mathrm{G}^{\prime \prime}=$ loss modulus.

${ }^{2}$ Values are presented as mean $\pm \mathrm{SD}$.

${ }^{3} \mathrm{CY}=$ control yogurt; $\mathrm{BY}=$ yogurt with $0.4 \%$ bovine gelatin; $\mathrm{FY}=$ yogurt with $0.4 \%$ fish gelatin. 

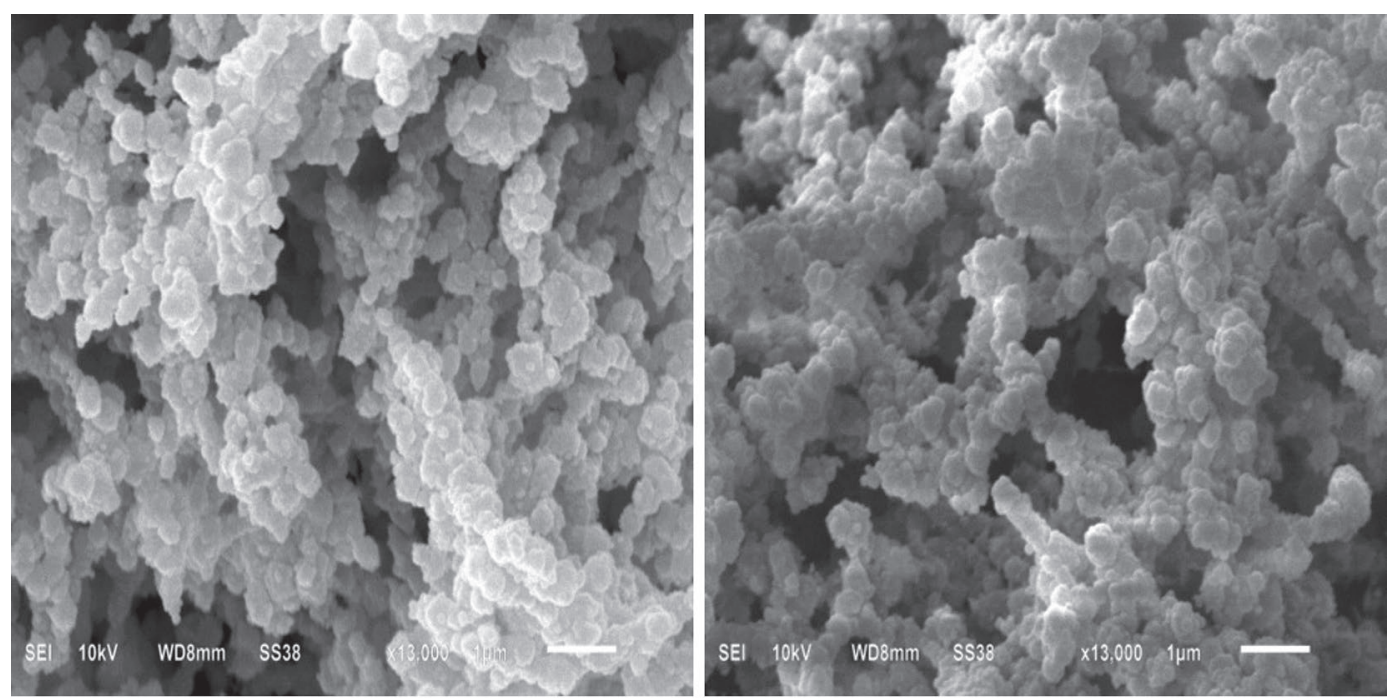

A

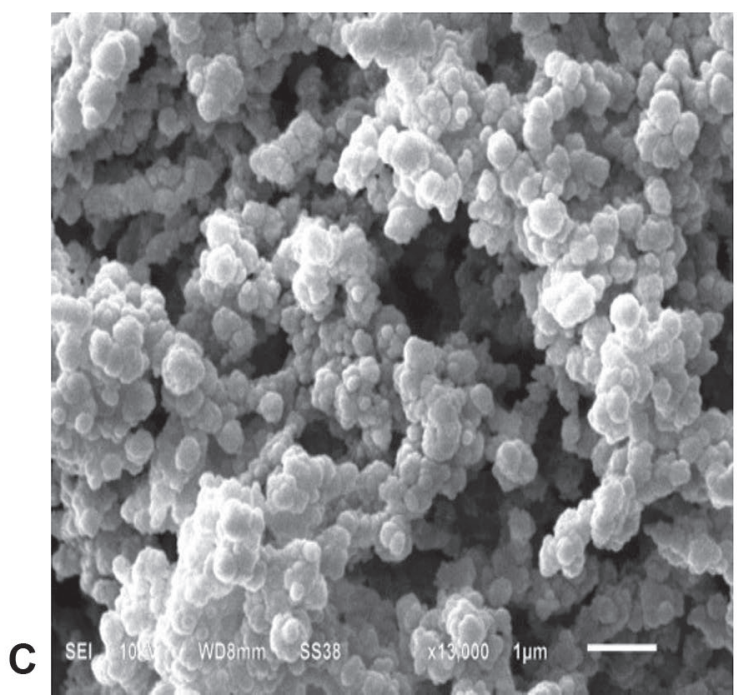

B

Figure 6. Scanning electron micrographs of yogurt without gelatin (CY; A), with $0.4 \%$ fish gelatin (FY; B), and with $0.4 \%$ bovine gelatin (BY; C). Scale bars $=1 \mu \mathrm{m}$.

\section{CONCLUSIONS}

This work evaluated the potential of TSG to replace mammalian gelatin in 3 systems (pure gelatin gels, acid milk gels, and yogurt). Gelling characteristics of TSG were investigated in pure gelatin gels. The TSG had lower gelling and melting temperatures and a higher gelation rate during the annealing stage than the BG; otherwise, the 2 gelatins had similar gelling and melting properties. Using acid milk gels as model systems, we monitored the 4 distinct stages during yogurt manufacturing and consumption by dynamic oscillatory rheology. The 2 gelatins were very similar during cooling and heating stages, and TSG was found to be very effective in improving the WHC of acid milk gels. Further, TSG behaved similarly to BG in terms of texture, WHC, rheology, and sensory aspects. Therefore, we concluded that the TSG used in this study was a suitable replacement for BG in low-fat stirred yogurt.

\section{ACKNOWLEDGMENTS}

The authors acknowledge the financial support of Dairy Innovation Australia. We also acknowledge the facilities, and the scientific and technical assistance, of the Australian Microscopy \& Microanalysis Research Facility at the Centre for Microscopy and Microanalysis, The University of Queensland.

\section{REFERENCES}

Adhikari, B., T. Howes, B. R. Bhandari, and V. Truong. 2001. Stickiness in foods: Mechanisms and test methods-A review. Int. J. Food Prop. 4:1-33. 
Amatayakul, T., A. Halmos, F. Sherkat, and N. Shah. 2006. Physical characteristics of yoghurts made using exopolysaccharide-producing starter cultures and varying casein to whey protein ratios. Int. Dairy J. 16:40-51.

Ares, G., D. Goncalvez, C. Perez, G. Reolon, N. Segura, P. Lema, and A. Gambaro. 2007. Influence of gelatin and starch on the instrumental and sensory texture of stirred yogurt. Int. J. Dairy Technol. 60:263-269.

Arnesen, J. A., and A. Gildberg. 2007. Extraction and characterisation of gelatine from Atlantic salmon (Salmo salar) skin. Bioresour. Technol. 98:53-57.

Beaulieu, M., S. L. Turgeon, and J. L. Doublier. 2001. Rheology, texture and microstructure of whey proteins/low methoxyl pectins mixed gels with added calcium. Int. Dairy J. 11:961-967.

Bourne, M. 2002. Food texture and viscosity: Concept and measurement. Academic Press, New York, NY.

Cavallieri, A. L. F., and R. L. Cunha. 2009. Cold-set whey protein gels with addition of polysaccharides. Food Biophys. 4:94-105.

Choi, S. S., and J. M. Regenstein. 2000. Physicochemical and sensory characteristics of fish gelatin. J. Food Sci. 65:194-199.

Cooney, M. J., M. Rosenberg, and C. F. Shoemaker. 1993. Rheological properties of whey-protein concentrate gels. J. Texture Stud. 24:325-334.

de Jong, S., H. J. Klok, and F. van de Velde. 2009. The mechanism behind microstructure formation in mixed whey protein-polysaccharide cold-set gels. Food Hydrocoll. 23:755-764.

Djabourov, M., J. P. Lechaire, and F. Gaill. 1993. Structure and rheology of gelatin and collagen gels. Biorheology 30:191-205.

Eastoe, J. E., and A. A. Leach. 1977. Chemical constitution of gelatin. Pages 73-107 in The Science and Technology of Gelatin. A. G. Ward, and A. Courts, ed. Academic Press, New York, NY.

Fiszman, S. M., and A. Salvador. 1999. Effect of gelatine on the texture of yoghurt and of acid-heat-induced milk gels. Z. Lebensm. Unters. F. A. 208:100-105.

Hassan, A. N., J. F. Frank, M. A. Farmer, K. A. Schmidt, and S. I. Shalabi. 1995. Formation of yogurt microstructure and threedimensional visualization as determined by confocal scanning laser microscopy. J. Dairy Sci. 78:2629-2636.

Hassan, A. N., R. Ipsen, T. Janzen, and K. B. Qvist. 2003. Microstructure and rheology of yogurt made with cultures differing only in their ability to produce exopolysaccharides. J. Dairy Sci. 86:1632-1638.

Haug, I. J., K. I. Draget, and A. Smidsrod. 2004. Physical and rheological properties of fish gelatin compared to mammalian gelatin. Food Hydrocoll. 18:203-213.

ISO. 2004. BS EN ISO 4120:2004 (Sensory Analysis. Methodology. Triangle Test. British Standards Institute.).

Jellouli, K., R. Balti, A. Bougatef, N. Hmidet, A. Barkia, and M. Nasri. 2011. Chemical composition and characteristics of skin gelatin from grey triggerfish (Balistes capriscus). Food Sci. Technol. 44:1965-1970.

Kalab, M., D. B. Emmons, and A. G. Sargant. 1975. Milk-gel structure. 4. Microstructure of yogurts in relation to presence of thickening agents. J. Dairy Res. 42:453-458.

Karim, A. A., and R. Bhat. 2009. Fish gelatin: Properties, challenges, and prospects as an alternative to mammalian gelatins. Food Hydrocoll. 23:563-576.

Keogh, M., and B. O'Kennedy. 1998. Rheology of stirred yogurt as affected by added milk fat, protein and hydrocolloids. J. Food Sci. 63:108-112.

Kumar, P., and H. N. Mishra. 2004. Mango soy fortified set yoghurt: Effect of stabilizer addition on physicochemical, sensory and textural properties. Food Chem. 87:501-507.
Leuenberger, B. H. 1991. Investigation of viscosity and gelation properties of different mammalian and fish gelatins. Food Hydrocoll. $5: 353-361$.

Loren, N., M. Langton, and A. M. Hermansson. 1999. Confocal laser scanning microscopy and image analysis of kinetically trapped phase-separated gelatin/maltodextrin gels. Food Hydrocoll. 13:185-198.

Lucey, J. A., T. van Vliet, K. Grolle, T. Geurts, and P. Walstra. 1997. Properties of acid casein gels made by acidification with gluconodelta-lactone. 1. Rheological properties. Int. Dairy J. 7:381-388.

Mahmoodani, F., V. S. Ardekani, S. F. See, S. M. Yusop, and A. S. Babji. 2014. Optimization and physical properties of gelatin extracted from pangasius catfish (Pangasius sutchi) bone. J. Food Sci. Technol. 51:3104-3113.

Maquet, J., H. Theveneau, M. Djabourov, J. Leblond, and P. Papon. 1986. State of water in gelatin solutions and gels-An H-1-NMR investigation. Polymer (Guildf.) 27:1103-1110.

Marcotte, M., A. R. Taherian Hoshahili, and H. Ramaswamy. 2001. Rheological properties of selected hydrocolloids as a function of concentration and temperature. Food Res. Int. 34:695-703.

Michon, C., G. Cuvelier, and B. Launay. 1993. Concentration-dependence of the critical viscoelastic properties of gelatin at the gel point. Rheol. Acta 32:94-103.

Pang, Z., H. Deeth, S. Prakash, and N. Bansal. 2016. Development of rheological and sensory properties of combinations of milk proteins and gelling polysaccharides as potential gelatin replacements in the manufacture of stirred acid milk gels and yogurt. J. Food Eng. 169:27-37.

Pang, Z., H. Deeth, R. Sharma, and N. Bansal. 2015. Effect of addition of gelatin on the rheological and microstructural properties of acid milk protein gels. Food Hydrocoll. 87:501-507.

Pang, Z., H. Deeth, P. Sopade, R. Sharma, and N. Bansal. 2014. Rheology, texture and microstructure of gelatin gels with and without milk proteins. Food Hydrocoll. 35:484-493.

Paseephol, T., D. M. Small, and F. Sherkat. 2008. Rheology and texture of set yogurt as affected by inulin addition. J. Texture Stud. 39:617-634.

Rahman, M. S., and A. I. Al-Mahrouqi. 2009. Instrumental texture profile analysis of gelatin gel extracted from grouper skin and commercial (bovine and porcine) gelatin gels. Int. J. Food Sci. Nutr. $7: 229-234$.

Saint-Eve, A., A. Juteau, S. Atlan, N. Martin, and I. Souchon. 2006. Complex viscosity induced by protein composition variation influences the aroma release of flavored stirred yogurt. J. Agric. Food Chem. 54:3997-4004.

Sanchez, C., R. Zuniga-Lopez, C. Schmitt, S. Despond, and J. Hardy. 2000. Microstructure of acid-induced skim milk-locust bean gumxanthan gels. Int. Dairy J. 10:199-212.

Sarabia, A. I., M. C. Gómez-Guillén, and P. Montero. 2000. The effect of added salts on the viscoelastic properties of fish skin gelatin. Food Chem. 70:71-76

Teles, C. D., and S. H. Flores. 2007. The influence of additives on the rheological and sensory properties of nonfat yogurt. Int. J. Dairy Technol. 60:270-276.

Walkenstrom, P., and A. M. Hermansson. 1994. Mixed gels of finestranded and particulate networks of gelatin and whey proteins. Food Hydrocoll. 8:589-607.

Walkenstrom, P., and A. M. Hermansson. 1996. Fine-stranded mixed gels of whey proteins and gelatin. Food Hydrocoll. 10:51-62.

Zhou, P., S. J. Mulvaney, and J. M. Regenstein. 2006. Properties of Alaska pollock skin gelatin: A comparison with tilapia and pork skin gelatins. J. Food Sci. 71:C313-C321. 